\title{
Erratum: Plasticity and ductility in graphene oxide through a mechanochemically induced damage tolerance mechanism
}

\author{
Xiaoding Wei, Lily Mao, Rafael A. Soler-Crespo, Jeffrey T. Paci, Jiaxing Huang, SonBinh T. Nguyen \\ \& Horacio D. Espinosa
}

Nature Communications 6:8029 doi: 10.1038/ncomms9029 (2015); Published 20 Aug 2015; Updated 7 Feb 2017

Professors SonBinh T. Nguyen and Jiaxing Huang were inadvertently omitted from the list of corresponding authors in this Article. The correct information for correspondence is: 'Correspondence and requests for materials should be addressed to H.D.E. (email: espinosa@northwestern.edu) or to J.H. (email: jiaxing-huang@northwestern.edu) or to S.T.N. (email: stn@northwestern.edu). 